TRANS · núm. I4 $\cdot 2010$

ARTICULOS · 99-115
Este artículo tiene como principal objetivo profundizar en las versiones realizadas por el escritor brasileño Manuel Bandeira de varios poetas de expresión española. Además de examinar las circunstancias que dieron lugar a tales traducciones, las cuales vieron la luz principalmente en la antología Poemas Traduzidos, por primera vez publicada en 1945, el presente estudio se ocupa también del pensamiento expuesto por el propio Bandeira a propósito de su concepción de la actividad traductora en el ámbito literario. Antes de finalizar, se presta atención especial al conjunto de poemas de la autoría de Juan Ramón Jiménez que aparecen en el volumen antes mencionado, ya que se trata del poeta español que mereció una mayor receptividad por parte de Bandeira en su faceta de traductor.

PalabRas ClaVe: Manuel Bandeira, Poemas Traduzidos, traducción poética, traductología brasileña, Juan Ramón Jiménez.

\title{
Manuel Bandeira, traductor de poetas en español al portugués de Brasil
}

\section{Manuel Bandeira as a Translator of Poetry from Spanish into Brazilian Portuguese}

The main objective of this article is to examine the translated versions of several Spanish-writing authors made by the Brazilian writer Manuel Bandeira. Besides examining the circumstances surrounding these translated versions, firstly published in the volume Poemas Traduzidos in 1945, the present work also refers to Bandeira's own view on the characteristics of literary translation. Finally, we focus on the collection of poems by Juan Ramón Jiménez published in the volume mentioned above, since he is the Spanish poet to whom Bandera devoted the greatest attention in his work as a translator.

Xosé Manuel Dasilva

Universidade de Vigo KEY WORDS: Manuel Bandeira, Poemas Traduzidos, Poetry Translation, Brazilian Translation Studies, Juan Ramón Jiménez. 
Figura destacada de las letras brasileñas de la primera mitad del siglo xx, Manuel Bandeira fue sobre todo poeta, pero también prosista, 100 cronista, antólogo, crítico, profesor universitario y además traductor. Desde el punto de vista de la historia literaria, se acostumbra a ubicar a Bandeira dentro del movimiento vanguardista brasileño en calidad de miembro de lo que se ha dado en denominar "grupo independente», al lado de autores como Tristão de Athayde, Sérgio Buarque de Holanda y Rodrigo Melo Franco de Andrade, puesto que su firme apuesta por lo novedoso no le hizo abjurar en ningún momento de lo antiguo (Azevedo Filho, 2005: 6-7). Ya Múcio Leão, en la «Nota preliminar» que aparecía en el volumen poético Estrela da Manbã — publicada por primera vez en 1936, con el título "Registro Literário», en Jornal do Brasil-, decía de él que era un «espírito de formação clássica, conhecedor profundo dos assuntos da filologia e da gramática», pero sin renunciar por ello a la «necessidade de infundirmos novo sangue e de imprimirmos novos rumos à poesia brasileira» (Bandeira, 1977: 226).

\section{LA ACTIVIDAD TRADUCTORA DE MANUEL BANDEIRA}

No constituye ninguna exageración afirmar que la traducción, principalmente del género poético, desempeñó un notable papel en la actividad de Bandeira como creador (Almeida, I989: 408). Por ejemplo, es posible encontrar en su obra un par de sorprendentes versiones intralingüísticas que él mismo designó como «Duas traduções para moderno acompanhadas de comentários». Se trata del soneto «Se é doce no recente, ameno estilo», perteneciente a Bocage, poeta portugués del siglo XVIII, y del poema «Adeus a Teresa», escrito por el

autor brasileño romántico Castro Alves, ambos incluidos en el libro Libertinagem. En la primera edición de este mismo volumen, publicada en I930, figuraban de igual modo las traducciones de tres sonetos de Elizabeth Barrett Browning calificadas como «admiráveis» (Monteiro, 1958: 33), que posteriormente Bandeira integró junto con una más en el libro Poemas Traduzidos. Por otra parte, en la obra $A$ Cinza das Horas está el soneto «Paráfrase de Ronsard», donde se aprecian un contenido y una imaginería tan típicos del poeta francés renacentista que casi parece que es una traducción.

Nuevamente en Libertinagem, Bandeira introdujo dos poemas escritos directamente en francés — «Chambre vide» $\mathrm{y}$ «Bonheur lyrique»-, y en Estrela da Manbã otro — "Chanson des petits esclaves»-, que en alguna ocasión pretendió autotraducir al portugués de $\mathrm{Bra}-$ sil, aunque sin que al final hubiese llegado tal experiencia a buen puerto, según confiesa en el libro Itinerário de Pasárgada, publicado en I954, que es toda una autobiografía literaria más que unas memorias convencionales (Bandeira, 1977: 79). Es conocida también una autotraducción en dirección inversa - esto es, del portugués al francés-, llevada a cabo por Bandeira luego de la lectura de una versión francesa de la composición «Poema de finados», de Libertinagem, por Michel Simon (Carelli, I995). Si se comparan estas dos traducciones, no es difícil observar, curiosamente, que las divergencias entre ambas son abundantes, y ya desde el mismo título: «Poème pour le jour des trépassés» en un caso y «Poème pour la jour des morts» en el otro.

Se ha puesto de relieve la extraordinaria destreza poética de Bandeira en el ámbito tanto de lo tradicional como de lo moderno (Teles, I985: 8I). Para él, la rima «traz ao ouvido uma sensação de surpresa, mas surpesa nascida não da raridade, senão de uma espécie de resolução 
musical», conforme declara en Itinerário de Pasárgada (Bandeira, I977: 45). Por otro lado, el verso libre supuso en su trayectoria una conquista, como él reconocía, tras comprender que «não é forçoso ficar no mesmo metro para manter o ritmo» (Bandeira, I977: 48). Justamente entre las dotes de Bandeira como traductor una de las que han sido más elogiadas es su magnífico dominio de la forma en toda su variedad métrica. Jorge Wanderley ejemplificó esta cualidad en el caso de su versión de Macbeth, donde el traductor se maneja con igual habilidad en las largas tiradas de endecasílabos y en los versos de arte menor (Wanderley, I988: 53).

Sin duda, la traducción constituyó una actividad ejercida ampliamente por Bandeira, en un momento inicial por necesidades económicas, y a partir de los años 30 hasta el final de su vida, por voluntad propia (Paes, 1990: 56). De hecho llegó a trabajar, al parecer, como traductor de telegramas de la agencia de noticias United Press. Bandeira poseía competencia en varias lenguas, entre ellas el francés y el alemán. Había perfeccionado estos idiomas durante su estancia en el sanatorio Clavadel, cerca de Davos-Platz, en Suiza, entre 1913 y 19I4, para tratar la tuberculosis que padecía, como cuenta en Itinerário de Pasárgada (Bandeira, 1977: 53). Dicha enfermedad la tuvo Bandeira desde los I8 años, y con ella se vio obligado a convivir amenazado permanentemente por la muerte:

Olhemos para trás. Quando caí doente em I904, fiquei certo de morrer dentro de pouco tempo: a tuberculose era ainda «a moléstia que não perdoa». Mas fui vivendo, morrenão-morre, e em I9I4 o Dr. Bodmer, médicochefe do sanatório de Clavadel, tendo-lhe eu perguntado quantos anos me restariam de vida, me respondeu assim: «O Sr. tem lesões teoricamente incompatíveis com a vida; no entanto está sem bacilos, come bem, dorme bem, não apresenta, em suma, nenhum sintoma alarmante. Pode viver cinco, dez, quinze anos... Quem poderá dizer?...». Continuei esperando a morte para qualquer momento, vivendo sempre como que provisoriamente. Nos primeiros anos da doença me amargurava muito a idéia de morrer sem ter feito nada; depois a forçada ociosidade. (Bandeira, I977: IOI)

Irónicamente, en el último verso de su poema «Auto-retrato» decía Bandeira que era «um tísico profissional». En el mencionado sanatorio de Clavadel trabó casualmente amistad con el poeta Paul Éluard y Gala, la posterior esposa de Salvador Dalí, entonces dos jóvenes casi desconocidos llamados Eugène Grindel y Elena Dimitrievna Diakonova.

En condición de traductor profesional o por encargo, entre la devoción y muchas veces la obligación, Bandeira vertió quince volúmenes para la editorial Civilização Brasileira y la Editora Nacional. Mencionemos algunos de los títulos: Nômades do Norte, de James Oliver Curwood; O Calendário, de Edgar Wallace; $O$ Tesouro de Tarzan, de Edgar Rice Burroughs; A Vida de Shelley, de André Maurois; Aventuras Maravilhosas do Capitão Corcoran, de Alfred Assolant; y Gengis-Khan, de Hans Dominick. Bandeira realizó asimismo trabajos para la «Coleção Nobel», dirigida por el escritor Érico Veríssimo, de la editorial Globo, que gozaba de un alto prestigio y en la que colaboró también el poeta Carlos Drummond de Andrade (Wyler, 2003: I29; Rónai, 2005: 5I).

A propósito de una buena parte de las versiones de Bandeira, Stefan Baciu estableció una pertinente distinción entre aquellas traducciones que se podría tachar de banales, aunque en ellas siempre haya puesto Bandeira el máximo cuidado, y otras que cabría considerar más especiales (Baciu, I966: 85). Dentro de estas últimas 
figuran primordialmente algunas piezas teatrales renombradas, como Macbeth, de Shakespeare, Maria Stuart, de Schiller, y A Máquina 102 Infernal, de Jean Cocteau — las dos primeras, de manera muy ilustrativa, recogidas en 1958 en el primer volumen de sus obras completas-.

Si tradujo en abundancia a otros, a Bandeira siempre le agradó a su vez ser vertido a otras lenguas, al contrario de lo que le ocurría, por ejemplo, al también poeta brasileño João Cabral de Melo Neto, a quien le perturbaba verse en idiomas foráneos (Dasilva, 2000-2002: 34-37). Bandeira experimentaba una grata alegría no solo por lo que la traducción podía suponer para la difusión de su obra, sino sobre todo por puro placer estético. Declara sin reservas en Itinerário de Pasárgada: «Assim como gosto de ser musicado, gosto de ser traduzido (no fundo é quase a mesma coisa, pois não é?). Sentir-me bem traduzido para outra língua, que delícia!» (Bandeira, 1977: 74). En la misma obra, Bandeira relata cómo disfrutó leyendo la versión de su poema «Mozart no Céu», de Lira dos Cinqüenta Anos, transferido al inglés por Dudley Poore. Le emocionaba la admirable correspondencia «turning marvelous pirouettes on a dazzling white horse» para el verso «fazendo piruetas extraordinárias sobre um mirabolante cavalo branco». Igualmente reconoce en Itinerário de Pasárgada que otro placer inmenso lo vivió con la versión italiana del poema «Boda espiritual», de A Cinza das Horas, por Giuseppe Ungaretti. Bandeira describía así esa satisfacción que sentía ante las traducciones de sus versos:

Sim, gosto de ser musicado, de ser traduzido e... de ser fotografado. Criancice? Deus me conserve as minhas criancices! Talvez neste gosto, como nos outros dois, o que há seja o desejo de me conhecer melhor, sair fora de mim para me olhar como puro objeto. (Bandeira, 1977: 74)

\section{MANUEL BANDEIRA Y LA ANTOLOGÍA POEMAS TRADUZIDOS}

Aparte de las versiones antes reseñadas, los frutos principales de Bandeira como traductor se encuentran en el volumen Poemas Traduzidos, cuya primera edición vio la luz en Río de Janeiro, publicada por R. A. Editora, en 1945. Al principio del libro se informa sobre los detalles de la tirada compuesta por trescientos cincuenta ejemplares, de los que cincuenta van numerados en romanos, doscientos setenta en árabes y veinticinco con la indicación «F. C.», es decir, «Fóra do Comércio». Con ilustraciones de Guignard, en esta primera edición aparecía un prólogo del propio Bandeira bajo el título «Advertência».

Este paratexto, de extensión breve, es interesante porque revela algunos pormenores sobre la génesis de Poemas Traduzidos. En efecto, Bandeira asegura que la mayoría de las ver- 
siones fueron producto de su quehacer como colaborador en el diario $A$ Manhã:

Não tinha eu a mínima intenção de recolher em livro as traduções que se vão ler. Isso porque, com exceção das que figuram nas minhas Poesias Completas e as de três ou quatro poemas de Juan Ramón Jiménez, não as fiz em virtude de nenhuma necessidade de expressão própria, mas tão-somente por dever de ofício, como colaborador do Pensamento da América, o suplemento mensal da Manbãa, ou para atender à solicitação de um amigo.

A idéia de as publicar em livro pertence a Murilo Miranda, que me tentou a vaidade acenando-me com uma edição ilustrada pelo grande Guignard. Cedi às suas instâncias, certo de que a arte do desenhista e o bom gosto do editor justificariam por si sós a publicação. (Bandeira, 1945: 9)

De manera no poco extraña, el referido texto introductorio desapareció en las siguientes ediciones de Poemas Traduzidos. El volumen se reeditó aumentado en 1948 por parte de Editora Globo, en Porto Alegre, aumentado nuevamente y revisado en 1956 por Livraria José Olímpio Editora, en Río de Janeiro, y finalmente, por la editorial José Aguilar en 1958, formando parte del primer tomo de los dos que constituían sus obras completas Poesia e Prosa. En este último caso, se incorporó un texto sobre Bandeira como traductor, con el título "Nota preliminar», de la autoría de Mário de Andrade, uno de los padres del Modernismo brasileño. A las mencionadas reediciones seguirían otras más adelante, aunque ya sin adiciones, lo que prueba el éxito de Poemas Traduzidos.

Bandeira se lamentó de varias erratas que se colaron en la primera edición, particularmente de una que desvirtuaba por completo el sentido de una estrofa del poema «Metade da vida», de Hölderlin. En lugar de la palabra «peras», que figuraba en la composición justo en posición inicial, se introdujo erróneamente «heras». No sin humor, Bandeira ponía en alerta a sus lectores en Itinerário de Pasárgada sobre esta errata:

Provavelmente o linotipista não acreditava que se pudesse misturar peras e rosas e imaginou que devia ser heras e não peras. Assim que, todos os que estas insossas memórias estiverem lendo, fiquem cientes que não escrevi nem jamais escreveria aquele horrendo verso Heras amarelas. (Bandeira, I977: 93)

Con respecto a los motivos que pudieron haber provocado la desaparición de la «Advertência», antes ya consignada, que encabezaba la primera edición de Poemas Traduzidos, no hay que descartar la influencia de un comentario de desaprobación del escritor y traductor Sérgio Milliet, vertido en el tercer volumen de la obra Diário Crítico. En su opinión, lo que Bandeira decía en tal nota preliminar, en especial sobre el hecho de que había llevado a cabo las versiones «em virtude de nenhuma necessidade de expressão própria, mas tão somente por dever de ofício», resultaba poco acertado al ser reflejo de una actitud doblemente presuntuosa:

Não me agrada a advertência [...]. E não me agrada porque não compreendo um grande poeta a traduzir sem «nenhuma necessidade de expressão própria». Há, ademais, na advertência um orgulho agressivo e o que é pior, «doublé» de vaidade. Orgulho por implicar a nota prefacial num mal disfarçado menosprezo às produções alheias «por dever de ofício traduzidas». Vaidade pela afirmação de segurança técnica que a publicação do trabalho artesanal exprime. (Milliet, I945: 53)

En la autobiografía literaria Itinerário de Pasárgada, Bandeira se hizo eco de esta objeción de Milliet justificando el sentido de lo que realmente quería transmitir en el pasaje en cuestión: 
A primeira edição dos Poemas Traduzidos trazia uma advertência em que eu explicava que a maioria das traduções apresentadas não as fizera eu «em virtude de nenhuma necessidade de expressão própria, mas tão-somente por dever de ofício, como colaborador do Pensamento da América, suplemento mensal d'A Manhã , ou para atender à solicitação de um amigo".

Sérgio Milliet meteu-me o pau por isso [...]. O bom Sérgio precisa reformar o seu juízo. [...]

Dizer que, «sem necessidade de expressão própria», traduzi um poema, não implica que o tenho em menosprezo. Há tantos grandes poemas que admiro de todo o coração e que traduziria «sem nenhuma necessidade de expressão própria». As Soledades de Góngora por exemplo. Mas é-se levado a pensar que o fato de traduzir inculca certa preferência. Era meu direito, sem sombra de orgulho, dar a entender que no meu caso não o havia. (Bandeira, 1977: 93-94)

En su definitiva cuarta edición, Poemas Traduzidos reúne textos de varias lenguas, lo que evidencia la vasta cultura idiomática de Bandeira, predominando, por este orden, el español, el inglés y el alemán, y en menor medida el francés y el italiano. De lengua inglesa aparecen, por ejemplo, poemas de Elizabeth Barrett Browning, Emily Dickinson, Christina Rossetti, Archibald McLeish, Langston Hughes, Elizabeth Bishop y e. e. cummings, mientras que de lengua alemana hay composiciones de Goethe, Heine, Rainer Maria Rilke, Hölderlin, Detlev von Liliencron, Gerhardt Houptmann y Stefan Zweig. En lo que respecta al francés, están representados Ronsard, Verlaine, Baudelaire, Francis Jammes y Paul Éluard, y del italiano constan la «Oração» de S. Francisco de Asís y poemas de Gribaldo Alessandrini, Claudio Allori, Aldo Capasso, Luigi Fiorentino y Araldo Sassone. Por último, hay cuatro haikús del japonés Matsuo Basho.

\section{LAS VERSIONES DEL ESPAÑOL EN POEMAS TRADUZIDOS}

En cuanto a la lengua española, el catálogo de poemas es, como hemos indicado, el más numeroso. Bandeira traduce, además del soneto anónimo clásico «No me mueve, mi Dios, para quererte», poesías de Antonio Machado («Canção»), García Lorca («Toada de Negros em Cuba» y «Balada da Pracinha») y Rafael Alberti («Lembra-te de mim no mar» $y$ «O Touro da Morte»). El ámbito hispanoamericano, por otra parte, aparece con profusión, puesto que tenemos textos entre otros de Sor Juana Inés de la Cruz («Redondilhas» y «Acalanto para Deus Menino»), Rubén Darío («Balada da Linda Menina do Brasil» y «O Fatal»), Gabriela Mistral («O Pensador de Rodin» y «Primeiro Soneto da Morte»), Nicolás Guillén («Elegia a Jacques Roumain no Céu de Haiti»), Jorge Luis Borges («Pátio»), Alfonso Reyes («A.») y los poetas vanguardistas panameños Homero Icaza Sánchez («Gota de Água») y Eduardo Ritter Aslán («Ode à Pátria»).

A mayores de lo que se contiene en Poemas Traduzidos, se hace inevitable apuntar que Bandeira trasladó del español al portugués de Brasil las obras Auto Sacramental do Divino Narciso, de Sor Juana Inés de la Cruz — también reproducida en sus obras completas-, D. João Tenório, de Zorrilla, Mireille, de Gabriel Mistral, y Os Verdes Campos do Éden, de Antonio Gala. En lo que concierne a su labor dentro de este par lingüístico, es preciso recordar el magisterio universitario de Bandeira como profesor de Literatura Hispanoamericana en la Faculdade Nacional de Filosofia de la Universidade do 
Brasil. Con esta ocupación se relaciona también el volumen Literatura Hispano-Americana, que vio la luz en 1949, y la disertación «Em louvor das letras hispano-americanas», editada dentro del libro 3 Conferências sobre Cultura HispanoAmericana en 1959, donde se reproducen además dos intervenciones del autor peruano Augusto Tamayo Vargas («Tres poetas de América») y la escritora brasileña Cecília Meireles («Expressão feminina da poesia na América»).

Por cierto, en la referida disertación de Bandeira asomaba una valiente denuncia del régimen franquista que no podemos dejar de copiar: «Hoje, porém, em todo o mundo as simpatias se voltam para o nobre país que foi no passado a barreira irredutível da cultura cristã e hoje é, desgraçadamente, o rebotalho das ditaduras fascistas que levaram o mundo à ruina». Por otro lado, habría que traer a colación algunas páginas del libro Noções de História das Literaturas, con varias ediciones, que salió inicialmente de la imprenta en 1940. Bandeira llegó a insertar en esta obra algunas líneas sobre 1a literatura catalana, mencionando a Josep Maria López-Picó, Josep Carner, Guerau de Liost, Josep Maria Sagarra, Joaquim Folguera, Joan Salvat-Papasseit y Tomàs Garcés, conforme le comunicaba al poeta João Cabral de Melo en una carta de 1947.

De las traducciones de Bandeira desde el español nos parece de justicia resaltar su versión del famosísimo Don Juan Tenorio, publicada por Edições do Serviço Nacional de Teatro en ig6o. Un año antes había sido representada en el Teatro Municipal de Río de Janeiro, con grandes aplausos, por el Teatro Nacional de Comédia, con escenografía y vestuario diseñados por Salvador Dalí. Aunque sea concisamente, ya que merecería por sí sola un extenso análisis, es necesario dejar al menos constancia de la excelente calidad de esta traducción.
Bandeira respetó la estructura del drama original, compuesto por dos partes, con cuatro actos la primera de ellas y tres la segunda. Desde el punto de vista estilístico, el traductor también procuró ser fiel a los procedimientos efectistas que se aprecian a lo largo de la obra: repeticiones de versos, expresiones y palabras, encabalgamientos, ripios, etc. Además, Bandeira se sujetó con sumo acierto a las pautas métricas de la obra de Zorrilla, las cuales dotan al texto de una gran sonoridad con diversas combinaciones en las que prevalece la rima consonante (redondillas, ovillejos, octavillas, décimas, cuartetos de endecasílabos, quintillas, etc.). Véase si no, como prueba incontestable de la pericia formal de Bandeira, este fragmento del acto segundo (escena r. ${ }^{a}$ ) de la primera parte:

(Don Luis Mejía, embozado)

Ya estoy frente de la casa de doña Ana, y es preciso que esta noche tenga aviso de lo que en Sevilla pasa. No di con persona alguna, por dicha mía... ¿Oh, qué afán!

Pero ahora, señor don Juan, cada cual con su fortuna. Si honor y vida se juega, mi destreza y mi valor, por mi vida y por mi honor, jugarán...; mas alguien llega.

Esta es la traducción al portugués de Brasil:

(D. Luís, embuçado)

Eis-me defronte do lar de Don'Ana. É-me preciso que eu the dê esta noite aviso do que aqui se vai passar. Por isso farei por vê-la. Grande é a minha inquietação. E agora, senhor D. João, cada qual com sua estrela. 
Não há viva alma, ainda bem!

Por minha honra, vida e amor, minha destreza e valor

106 bater-se-ão... Mas chega alguém.

\section{EL PENSAMIENTO TRADUCTOR DE MANUEL BANDEIRA}

Bandeira proporcionó algunas reflexiones sobre el ejercicio de traducir y hasta se ha llegado a debatir si sería factible hablar de la existencia de una teoría bandeiriana de la traducción literaria. Sea como fuese, lo más correcto tal vez sea considerar que hay propiamente opiniones fragmentarias derivadas de su experiencia, y por ello Jorge Wanderley avanzó con acierto esta valoración:

Há em Manuel Bandeira uma teoria da tradução toda feita de instintos. Sua ars poetica neste campo não é suficientemente explicitada e deve, por força, basear-se mais na dedução de princípios a partir das traduções realizadas e do processo em si, sem subsídios maiores que o poeta tenha fornecido. (Wanderley, I988: II)

En la esfera de las crónicas y las cartas, Guimarães hizo referencia, de tal forma, a una misiva de Bandeira dirigida en 1946 al poeta Alphonsus de Guimaraens Filho, donde figuraba la siguiente recomendación (Guimarães, I989: 366):

Mas aqui peço licença para lhe dar uma lição: sempre que você quiser traduzir um poema, faça um estudo preliminar no sentido de apurar o que é essencial nele e o que foi introduzido por exigência técnica, sobretudo, de rima e métrica. Isto feito, se aparecerem dificuldades que digam respeito ao último elemento (o que não é essencial e pode ser alijado), resolva-as alijando o supérfluo, mesmo que seja bonito. (Bandeira, I958, II: I433)

Según se comprueba, lo que se acaba de transcribir no constituye una formulación teórica, sino que es principalmente una noción técnica adquirida tras una larga práctica. Tal como recordó José Paulo Paes, la mayor parte de las ideas que Bandeira expuso alrededor del hecho traductor se hallan en la autobiografía literaria Itinerário de Pasárgada (Paes, I990: 56), procediendo casi todas de los comentarios críticos suscitados por sus versiones. Es el caso de la referencia que introduce en dicho volumen sobre lo que opinó Abgar Renault de varias de sus traducciones inglesas. Bandeira, con actitud modesta, resta méritos a sus aciertos y no esconde que solamente traduce aquellas poesías que le gustaría haber escrito:

Gostaria que fosse verdade o louvor tão lisonjeiro de meu querido amigo Abgar. Mas devo confessar que sou bastante fundo no inglês. Fundo no sentido que a palavra tem na gíria. Todas aquelas soluções julgadas tão felizes pelo crítico, por mais cavadas ou sutis que pareçam, devem se ter processado no subconsciente, porque as traduções me saíram quase ao correr do lápis. Antes, houve, sim o que costumo fazer quando traduzo; deixar o poema como que flutuar por algum tempo dentro do meu espírito, à espera de certos pontos de fixação. Aliás só traduzo bem os poemas que gostaria de ter feito, isto é, os que exprimem coisas que já estavam em mim, mas informuladas. Os meus achados, em traduções como em originais, resultam sempre de intuições. (Bandeira, 1977: 92-93)

Bandeira también alude en Itinerário de Pasárgada a las observaciones contenidas en el Diário Crítico de Sérgio Milliet a propósito de Poemas Traduzidos. Concretamente, y como apostilla a lo que este consideraba sobre una 
traducción de Christina Rossetti, reconoce los escollos casi insalvables que encierra la transferencia de determinados poetas:

Há versos que nem quebrando a cabeça semanas a fio consigo traduzir. Não se trata de poesia intraduzível por sua própria natureza, como a de Mallarmé ou a de Valéry, em que a emoção poética está rigorosamente condicionada às palavras (e foi, creio, nesse sentido que Mallarmé disse a Degas que a poesia se faz com palavras e não com sentimentos), mas de poesia traduzível até em prosa. (Bandeira, I977: 93)

Para finalizar esta somera revisión del pensamiento traductológico de Bandeira, nos parece adecuado dejar constancia de otro juicio sobre el que Benedito Antunes llamó la atención, incluido en este caso en el libro de crónicas Andorinha, andorinha, donde se expresa, en la estela de Benedetto Croce, la relevancia que una versión puede poseer como producto original:

Toda tradução é impossível se pretende o transvasamento de uma expressão em outra, como o líquido de um recipiente a outro; não podemos reduzir o que já tem forma estética a outra forma estética. Toda tradução, com efeito, ou diminui e estropia, ou cria uma expressão nova. Assim, a tradução que merece o nome de boa é uma aproximação que tem valor de obra de arte, e que pode viver independentemente. (Antunes, I99r: 4)

\section{ACERCA DE LA REPERCUSIÓN DE POEMAS TRADUZIDOS}

Jorge Wanderley puso de manifiesto el hito que marcó en su momento la irrupción de Poemas Traduzidos. Hasta entonces, ninguna antología de versiones poéticas publicada en Brasil había tenido tan buena aceptación, dado que la costumbre era que todas ellas acabasen al poco tiempo en el olvido. Esta situación vino a alterarla completamente Poemas Traduzidos, acaso porque la obra se recibió como si las poesías fuesen del propio Bandeira y no traducciones. Wanderley aportó otras causas que también pudieron haber intervenido en la cálida recepción del volumen:

O livro ganhou imediata e longeva cidadania (vige até hoje), o que se deve a muitos fatores. Em primeiro lugar, a qualidade das traduções, há muito reconhecida, embora nenhuma análise se detivesse mais profundamente nas micrologias do trabalho; depois, a escolha dos poetas (Baudelaire, Emily Dickinson, etc.), que suscitava boa repercussão no público leitor da área; e finalmente a seleção dos poemas, que juntava no todo textos consagrados e peças menores mas que tinham, estas, grande penetração, por acessíveis, dóceis principalmente a um leitor já afeito à tônica musical, verbal e temática do próprio Bandeira. (Wanderley, I988: 62-63)

Sin ningún atisbo de duda, Poemas Traduzidos fue un volumen bastante celebrado desde el momento de su aparición, mereciendo diversos comentarios y estudios. De Sérgio Milliet expusimos ya algunos reparos a la "Advertência» de la primera edición, si bien el mismo autor no dejaba de enjuiciar favorablemente las versiones bandeirianas: «Tais traduções valem como obras de arte» (Milliet, I945: 152). Así valora, por ejemplo, la versión del poema «Canção», de Christina Rossetti:

Se se colocar em frente desse texto o original inglês ter-se-á uma idéia precisa daquilo que eu insisto em denominar equivalência e que consiste não na tradução exata das palavras, mas na expressão do mesmo sentimento, e até das mesmas imagens, sob forma diferente. (Milliet, 1945: 15I) 
Ahora bien, es imprescindible subrayar que el elogio de Milliet no era absolutamente entregado, puesto que en las mismas páginas del 108 Diário Crítico enaltece las aptitudes traductoras del también poeta Guilherme de Almeida de una forma mucho más entusiástica:

Guilherme de Almeida, nessas traduções, evidencia mais uma vez seu espantoso domínio da língua, sua profunda intimidade com a técnica do verso, seu espírito inventivo inigualável. Não sei de artista mais completo na atualidade literária brasileira, nem de artífice mais hábil e capaz. (Milliet, 1945: 147)

E1 escritor Mário de Andrade dedicó igualmente atención a las poesías vertidas por Bandeira. Lo hizo en el prólogo añadido a la cuarta edición de Poemas Traduzidos con el título "Nota preliminar», en su origen un artículo publicado en el Diário de Notícias, de Río de Janeiro, a los pocos días de salir de la imprenta la primera edición del volumen. Mário de Andrade reflexiona al comienzo sobre el camino que hay que seguir para vencer los obstáculos que entraña toda traducción poética. A su modo de ver, lo importante es lograr que el producto traducido no pierda en la operación traslativa los ingredientes estéticos del poema de partida:

Filosoficamente, nós todos sabemos que poesia é intraduzível, e eu sou daqueles que afirmam que, dentro dela, street ou calle não correspondem a rua. $\mathrm{Na}$ verdade os poemas não são traduzíveis; em poesia, há que conceituar a tradução como um processo de substituição. $\mathrm{O}$ que o tradutor faz é substituir um objeto por outro, apenas observando do primeiro, para efeitos da substituição, o elemento funcional (o assunto) e as suas conseqüências estéticas (a realização técnica). O segredo na substituição poética, não é tanto preservar o

Como muestra, Mário de Andrade profundiza en la versión de Bandeira de un poema del autor norteamericano Langston Hughes, la cual le conduce a sentenciar: «Mas Deus me perdoe se eu não prefiro a tradução do grande Manuel Bandeira ao poema do grande Langston Hughes» (Andrade, I958: 570). Ensalza a continuación el trabajo de varios traductores brasileños a la vez poetas, como Abgar Renault, Guilherme de Almeida y Onestaldo de Penafort, además del propio Bandeira. De este, Mário de Andrade hace hincapié en su «poder de desistência de si mesmo», es decir, en la capacidad para reproducir voces ajenas sin que interfiera en ningún instante la suya. Luego concluye que en Poemas Traduzidos se verifica que Bandeira es «um especialista na tradução», hasta el extremo de que las versiones constituyen momentos brillantes incluso en el conjunto de su poesía: «E quase todos estes são momentos mais elevados, não apenas da tradução, mas a meu ver da própria poesia de Manuel Bandeira» (Andrade, I958: 572).

El citado Abgar Renault se encargó asimismo de juzgar las traducciones de Bandeira, destacando la importancia de sus versiones inglesas, en particular de los sonetos de Elizabeth Barrett Browning. Piensa Renault que estos sonetos, en manos de Bandeira, «não sabem a traduções, senão a produções originais» (Renault, I936: 26), en virtud de su forma, su intensidad y su nueva vida. A la vista de tales versiones, también estudiadas por Giovanni 
Pontiero (1962), Renault concluye que pueden ser consideradas con toda legitimidad una parcela de la propia obra de Bandeira:

São das páginas mais consideráveis de Manuel Bandeira as traduções de alguns poemas ingleses, que podem ser incorporados à sua obra como produção própria, sem embargo da fidelidade ao original, tais a assimilação e a absorção dos textos estrangeiros, da sua forma, da sua técnica e do seu espírito à forma, à técnica, ao espírito do tradutor. Quero dizer: o que há de indizível nos poemas, a sua parte de silêncio, que transcende o verbo e flutua, como uma aura, acima da forma e da técnica —isso, que é tudo em poesia, foi transportado para a nossa língua com uma assombrosa felicidade. (Renault, 1936: 25)

Cabe hacer mención, aunque solo sea nominalmente, de otras aproximaciones a Bandeira como traductor. Recordemos, en una relación sucinta, los estudios de Guimarães (1989) y Almeida (1989) —de enfoque global—, Galeão (r989) y Sager (r966) — sobre las traducciones del alemán—, Martini (1989) — con referencia a algunas versiones del español—, Pontiero (1964) —de Macbeth-, Ramos (1998) —en torno a Elizabeth Bishop-y Rossi (1970, 197I) — sobre Sor Juan Inés de la Cruz-.

\section{LOS POEMAS DE JUAN RAMÓN JIMÉNEZ TRADUCIDOS POR MANUEL BANDEIRA}

Volviendo a la colectánea Poemas Traduzidos, se debe hacer notar que, ya desde la primera edición, un lugar de privilegio lo ocuparon en ella las poesías de Juan Ramón Jiménez. Como indicio de la entidad conferida, no es casualidad que apareciesen agrupadas bajo un epígrafe común debidamente señalado: «Trinta e duas canções de Juan Ramón Jiménez».
Otro argumento que apoya el peso de las piezas del poeta de Moguer en Poemas Traduzidos es la circunstancia de que Bandeira no hubiese traducido de ningún otro autor tantos poemas. El que más se acerca a Juan Ramón Jiménez es Hölderlin, y aun así queda a bastante distancia, ya que suyas son solamente nueve composiciones. La selección de los textos juanramonianos, que pertenecen a varios libros, denota a las claras el deseo por parte del traductor de abarcar un amplio segmento de su biografía literaria. He aquí enumerados los títulos de los poemas: «A Menina Idílio», «Pavilhão», «A Viagem Definitiva», «Deus do Amor», «O Tesouro», «Olhos de Ontem», «De Volta», «A Castigada», «A Paz», «Tu», «Meu Sítio», «As Ilusões», «Jogo», «A Ausente», «Grácil», «A Noite», «Universo», «Virtude», «Deserto e Mar», «Tua Nudez», «O Estudante», «A Única Rosa», «Contigo, Comigo», «O Perigo», «Minha Cabra», «Primavera», «Fim de Inverno», «Branco», «Agridoce», «Glória Baixa», «O Único Amigo» $\mathrm{y}$ «Canção de Canções».

Desde el punto de vista cuantitativo, las versiones de Bandeira ostentan un lugar preeminente entre las traducciones juanramonianas a la lengua portuguesa. Ciertamente, en Portugal solo es posible citar Platero e Eu (Lisboa, Livros do Brasil, I957) y una Antologia Poética (Lisboa, Relógio d'Água, 1992), ambos volúmenes trasplantados por José Bento. En lo que respecta al territorio brasileño, se registra únicamente una nueva versión de Platero e Eu (Río de Janeiro, Editora Globo, I953), de Athos Damasceno. Con estos datos corresponde afirmar, por tanto, que la de Bandeira supuso la primera traducción del poeta andaluz en el espacio lusófono.

No resulta fácil establecer los motivos que condujeron a Bandeira a llevar a cabo estas versiones. Por lo general, se ha tratado de identificar el móvil que dio lugar a que en un determi- 
nado momento resolviese trasladar a un autor. Jorge Wanderley, así, se refirió a la influencia de diversas causas, como una cierta sintonía con el texto, la solicitud de terceras personas o una reacción repentina. Stefan Baciu estimó que Poemas Traduzidos encarna «uma antologia bandeiriana universal» (Baciu, 1966: 90), pero a juicio de Wanderley no existe ningún tipo de planificación detrás de la selección plasmada en el volumen:

Como pretendemos comentar mais adiante e em maior minudência, as traduções em Banderia não constituem, em si mesmas, um corpus definidor de programa; antes definem o próprio casual do poeta, o embalo e a oscilação de circunstâncias bastante típicas de seu temperamento e de seu tempo. (Wanderley, 1988: 27)

Con relación a Juan Ramón Jiménez, sí se sabe que era uno de los poetas españoles preferidos de Bandeira junto con algunos otros presentes en Poemas Traduzidos. En un reportaje literario de Paulo Mendes Campos, publicado en O Jornal, de Río de Janeiro, y más tarde recogido en las obras completas Poesia e Prosa, Bandeira reconocía esta primacía del autor de Platero y yo:

Meus poetas preferidos? É muito fácil responder a essa pergunta. Depende da hora, das circunstâncias. [...] Assim, na Espanha os poetas do Siglo de Oro, no romantismo Bécquer, entre os modernos Jorge Guillén, Antonio Machado, Juan Ramón Jiménez, Lorca, Alberti e outros. (Campos, I958: II74)

Por consiguiente, parece claro que la atracción estética hacia Juan Ramón Jiménez fue el desencadenante de que Bandeira se hubiese decidido a traducirlo. Según el traductor brasileño Geir Campos, de amplia experiencia, esta suele ser una de las razones que propician

la elección del texto que se traduce: «O tradutor deve sentir-se de algum modo atraído ou motivado, ou pela forma ou pelo conteúdo dele, ou pelo autor, ou pela cultura do lugar a que se refere o texto a traduzir» (Campos, 1986: 71).

Existe un artículo de Bandeira sobre Juan Ramón Jiménez publicado el 3r de octubre de I956, con motivo de la concesión unos días antes del Premio Nobel, reproducido después en el libro de crónicas Flauta de papel, que resulta muy iluminador. En él, Bandeira refleja su admiración por el poeta y un conocimiento más que aceptable de su evolución lírica:

Pela terceira vez é a Espanha contemplada com o Prêmio Nobel de Literatura. Mal dado das duas primeiras vezes. Não é que a Espanha não o merecesse. Merecia-o, sim, mas não nas pessoas de Echegaray ou Benavente. Galdós, Unamuno, foram preteridos.

Agora os suecos acertaram laureando uma figura de espanhol realmente excepcional - $\mathrm{O}$ poeta de Eternidades, o prosador de Platero y yo, mestre D. Juan Ramón Jiménez, andaluz como Góngora e Lorca, «andaluz universal».

Dele disse González Ruano haver fechado com lograda plenitude o parêntese aberto por Rubén Darío. Na verdade assim sucedeu: Juan Ramón Jiménez foi, nos seus primeiros livros, de Almas de violeta até os Sonetos espirituales, a última flor de perfume próprio no versalhesco parque modernista. Em I9I7, coincidindo com o casamento do poeta, começa a fase de depuramento: intelijencia, dame / el nombre exacto de las cosas! / Que mi palabra sea / la cosa misma, I creada por mi alma nuevamente.

Em outro poema famoso desse mesmo livro das Eternidades conta ele como chegou à sua poesia definitiva, ou, mais exatamente, como ele chegou a ele. Veio, primeiro, pura, vestida de inocência; depois, se foi trajando de ricas roupagens, como uma rainha; por fim, se pôs a desnudar-se, voltou à túnica de sua antiga inocência; quando a lançou de si e apareceu 
toda nua, gritou-lhe o poeta: ;Oh pasión de mi vida, poesía / desnuda mía para siempre!

$O$ poeta alcançara a singeleza e a espontaneidade por ele definidas - a primeira como o conseguido com o menor número de elementos possível, a segunda como o criado sem esforço. A melhor poesia de Juan Ramón Jiménez é isso: o universo refletido numa pelúcida gota de água. (Bandeira, I958, II: 482-483)

Dígase de paso que, a principios de I946, Bandeira le enviaba a Alphonsus de Guimaraens Filho, con mucho empeño, un ejemplar del libro Sonetos espirituales. En el artículo citado, el poeta brasileño también pone al descubierto la incitación que le llevó a traducir a Juan Ramón Jiménez y el criterio que guió la selección de los versos:

Quando tomei contato com esse extraordinário mundo lírico, logo tentei trasladar um pouco de sua música para a nossa língua. E traduzi o que me parecia mais fácil, trinta e duas de suas inefáveis canções, poemas de várias épocas, desde a primeira inocência até o desnudamento. (Bandeira, I958, II: 483)

Es conveniente traer de nuevo a la memoria aquello que Bandeira decía sobre algunas de las poesías de Juan Ramón Jiménez en la «Advertência» de la primera edición de Poemas Traduzidos. Efectivamente, testimoniaba que, al lado de otras traducciones que aparecen en sus obras completas — el soneto «Paráfrase de Ronsard» y los sonetos de Elizabeth Barrett Browning-, tales versiones habían surgido del deseo de alcanzar una «expressão própria». No se nos antoja casual, en ese sentido, que Juan Ramón Jiménez sea, como ya hemos advertido, el poeta que aparece con mayor número de composiciones en Poemas Traduzidos. Tampoco es fortuito que sus versiones se distingan de forma expresa en el volumen con el epígrafe «Trinta e duas canções de Juan Ramón Jiménez». Ambos detalles son prueba incuestionable de que los textos del creador de La soledad sonora merecieron una cuidada atención por parte de Bandeira a lo largo de su actividad como traductor.

Como muestrario mínimo de las versiones de Juan Ramón Jiménez reunidas en Poemas Traduzidos, ofrecemos a continuación algunos ejemplos. Fijémonos, en primer lugar, en el poema «Ojos de ayer», del libro Las hojas verdes (I9I9):

¡Ojos que quieren

mirar alegres

y miran tristes!

¡No, no es posible

que un muro viejo

dé brillos nuevos, que un seco tronco

(abra otras hojas)

abra otros ojos

que éstos,

que quieren

mirar alegres

y miran tristes!

¡No, no es posible!

Esta es la traducción de Bandeira:

Olhos que querem

olhar alegres

e olham tão tristes!

Ai, impossível

que um muro velho

dê brilhos novos;

que um tronco seco

abra outras folhas,

abra outros olhos

que estes, que querem

olhar alegres

e olham tão tristes!

Ai, impossível! 
Véase, además, el poema «Mi sitio», de la antología Canción (1936):

\begin{abstract}
Tarde última y serena, corta como una vida, fin de todo lo amado ¡yo quiero ser eterno!

(Atravesando hojas, el sol ya cobre viene a herirme el corazón. ¡Yo quiero ser eterno!)

Belleza que yo he visto ¡no te borres nunca! Porque seas eterna ¡yo quiero ser eterno!
\end{abstract}

Así lo tradujo Bandeira:

Tarde última e serena, curta como uma vida, fim de tudo que amei, eu quero ser eterno!

Atravessando folhas, o sol, já cobre, vem ferir-me o coração. Eu quero ser eterno!

Beleza que fitei, oh não te apagues nunca! Para que eterna sejas, eu quero ser eterno!

\section{UNA CARTA INÉDITA DE JUAN RAMÓN JIMÉNEZ A MANUEL BANDEIRA}

El legado documental de Bandeira se custodia hoy en día en la Fundação Casa de Rui Barbosa, en Río de Janeiro (Silva \& Lessa, I989). Con referencia a su faceta de traductor, entre los materiales conservados en esta institución se hallan diferentes cartas. Por ejemplo, constan cinco misivas enviadas a Bandeira por la Editora Vozes, entre el 26 de enero y el I5 de julio de 1965 , entre las cuales se adjunta el contrato para una versión de El gran teatro del mundo, de Calderón de la Barca, y se habla del pago de las traducciones de Los verdes campos del Edén, de Antonio Gala, y La hoguera feliz, de José Luis Martín Descalzo. Por otra parte, aparecen dos cartas enviadas por la Fundação Calouste Gulbenkian, el 6 de agosto y el 2 de septiembre de 1964, solicitando autorización a fin de utilizar su traducción de Macbeth con motivo de las conmemoraciones del cuarto centenario de la muerte de Shakespeare. Se pide permiso, singularmente, para introducir en la versión diversas modificaciones con el objeto de adaptar al portugués de Portugal algunas expresiones del texto traducido al portugués de Brasil.

En el mismo legado documental, se encuentran dos cartas a Bandeira del poeta cubano Nicolás Guillén, del 2 de octubre de 1948 y el I de febrero de 1949, en las que este le informa de que está tratando de transvasar algunos poemas suyos al español. Asimismo se guardan tres cartas del prestigioso traductor alemán Curt Meyer-Clason, con fechas desde el 4 de mayo al I2 de junio de 1965, donde comenta los impedimentos que tiene para poner en alemán algunos de sus textos.

Sería posible dar cuenta de otras sugestivas cartas a Bandeira disponibles en la Fundação Casa de Rui Barbosa. Algunas de ellas incluso tienen como protagonista a Juan Ramón Jiménez, como dos comunicaciones de la Editora Celta, del I2 de julio de 1956 y del 22 de agosto de 1962 , donde se refiere al acuerdo para la publicación de varios poemas en un volumen dedicado al escritor dentro de la colección Prêmios Nobel. Para nuestro interés en este estudio, sin embargo, el documento más valioso es una carta de Zenobia Camprubí al autor brasileño, 
hasta ahora desconocida, firmada en Hato Rey por ella misma y Juan Ramón Jiménez el 5 de abril de I955. El valor que este documento atesora está acreditado, sin duda, a diversos efectos.

En primer lugar, of rece algunos pormenores biográficos sobre la vida del insigne matrimonio durante las últimas fechas, remontándose a años anteriores. Zenobia confidencia lo que supuso para la vida del poeta el traslado a Puerto Rico a comienzos de los años cincuenta, y refiere además las dificultades por las que atravesó la salud de aquel en los primeros meses de 1955. Estas noticias, ciertamente, complementan de forma estimable lo referido por Zenobia acerca de este período en su Diario (Camprubí, 2006a) y en el epistolario a Juan Guerrero Ruiz (Camprubí, 2006b). En segundo lugar, la carta a Bandeira es también importante porque refleja la impresión favorable que les merecieron las versiones de Poemas Traduzidos a Zenobia y Juan Ramón Jiménez —él mismo, no se olvide, traductor de poetas, como se comprueba en el volumen recopilatorio Música de otros (Traducciones y paráfrasis), de reciente aparición-.

Como final de nuestro estudio, transcribimos seguidamente el contenido íntegro de dicha carta recordando una vez más su carácter inédito:

\section{Sr. D. Manuel Bandeira}

E1 Brasil.

Muy Sr. mío y amigo:

Después de cuatro meses de hospitalización y mes y medio de convalecencia en casa, mi marido, Juan Ramón Jiménez, que ha tenido mucho tiempo de estancamiento para recordar su correspondencia abandonada de ahora y de antes, me pide que le escriba a Vd., en su nombre, diciéndole cuánto agradeció sus libros, en uno de los cuales pudo leer las preciosas traducciones que Vd. hizo de canciones de él y la alegría que le causaron. Uno de los motivos que tuvo para no escribir a Vd. entonces, era nuestro aislamiento del ambiente propio, en la Universidad de Maryland, en donde no sabíamos a quien dirigirnos para averiguar su dirección.

En el 50 Juan Ramón se sintió ya tan enfermo que decidimos venir a Puerto Rico, para encontrar en un ambiente mucho más parecido al suyo algún alivio a su mal. E1 experimento resultó favorable y, después de un retorno al norte, para liquidar nuestros asuntos allá y organizar nuestro regreso a esta isla, lo hicimos definitivamente en el 5r. Juan Ramón mejoró tanto que ha pasado dos años magníficos, trabajando en esta generosa y simpática universidad, junto a nuestro amigo, el dinámico rector, Jaime Benítez. Desgraciadamente, Juan Ramón ha tenido una recaída reciente con los resultados que apunté al comenzar mi carta. Ni qué decir tiene que nuestros libros nos han seguido lentamente cuando estábamos ya convencidos de que este era nuestro lugar definitivo. Estas enfermedades, traslados y dispersiones nos han hecho cumplir muy mal con todos nuestros amigos y más con personas con quienes estábamos, como con Vd., en gran deuda.

Ayer, en casa del Prof. Onís, vi una revista americana con poesías de $\mathrm{Vd}$., traducidas por Dña. Harriet Onís y, al momento, pregunté cómo comunicarme con Vd. Ella no sabía su dirección pero recomendó que enviara esta carta a la casa editora de la revista, diciéndome que era seguro que la reexpedirían.

Le rogamos que perdone el retraso increíble de esta carta, no por tardía menos sincera.

Sus agradecidos amigos

Zenobia C. de Jiménez Juan Ramón Jiménez

RECIBIDO EN ENERO DE 2009

ACEPTADO EN ABRIL DE 2009

VERSIÓN FINAL DE SEPTIEMBRE DE 2009 


\section{REFERENCIAS BIBLIOGRÁFICAS}

Almeida, Lilian Pestre de (I989). «Manuel Bandeira

114 e o universo das correspondências (A tradução e as artes plásticas na obra de Bandeira)». En Maximiano de Carvalho e Silva, org., Homenagem a Manuel Bandeira 1986-1988, Niterói: Presença Edições, pp. 407-415.

Andrade, Mário de (1958). «Nota preliminar». En Manuel Bandeira, Poesia e Prosa, vol. I, Río de Janeiro: Editora José Aguilar, pp. 569-573.

Antunes, Benedito (I99I). «Notas sobre a Tradução Literária». Alfa, 35, pp. I-ıо.

Azevedo Filho, Leodegário A. (2005). Modernismos e Pós-modernismos na Literatura Brasileira. Uma Visão Geral, Río de Janeiro: H. P. Comunicação Editora.

Baciu, Stefan (1966). Manuel Bandeira de Corpo Inteiro, Río de Janeiro: Livraria José Olímpio Editora.

Bandeira, Manuel (1945). Poemas Traduzidos, Río de Janeiro: R. A. Editora.

Bandeira, Manuel (1958). Poesia e Prosa, Río de Janeiro: Editora José Aguilar. 2 vols.

Bandeira, Manuel (I959). «Em louvor das letras hispano-americanas». En 3 conferências sobre cultura bispano-americana, Río de Janeiro: Ministério da Educação e Cultura, pp. 5-I8.

Bandeira, Manuel (1977). Poesia Completa e Prosa, $4^{\text {a }}$ ed., Río de Janeiro: Editora Nova Aguilar.

Campos, Geir (I986). O que é a tradução, São Paulo: Brasiliense.

Campos, Paulo Mendes (1958). «Reportagem literária». En Manuel Bandeira, Poesia e Prosa, vol. I, Río de Janeiro: Editora José Aguilar, pp. II59-II75.

Camprubí, Zenobia (2006a). Diario 3. Puerto Rico (I95I-1956), Madrid: Alianza Editorial-La Editorial Universidad de Puerto Rico. Edición, traducción, notas y epílogo de Graciela Palau de Nemes.

Camprubí, Zenobia (2006b). Epistolario I. Cartas a Juan Guerrero Ruiz I9I7-I956, Madrid: Publicaciones de la Residencia de Estudiantes. Edición de Graciela Palau de Nemes.

Carelli, Mario (I995). «Bandeira retraduit Bandeira». En Celine da Cunha Pereira; Paulo Roberto Dias Pereira, orgs., Miscelânea de estudos lingüísticos, filológicos e literários in Memoriam Celso Cunha, Río de Janeiro: Nova Fronteira, pp. 807-8I2.

Dasilva, Xosé Manuel (2000-2002). «Não era só um outro país, era um outro universo (Alrededor de João Cabral de Melo traducido al español)», Cadernos de Tradução, 6, pp. 33-54.

Galeão, Celeste Aída (I989). «Manuel Bandeira, tradutor de poetas alemães». En Maximiano de Carvalho e Silva, org., Homenagem a Manuel Bandeira I986-I988, Niterói: Presença Edições, pp. IoI-I22.

Guimarães, Júlio Castañón (I989). «O tradutor Manuel Bandeira». En Maximiano de Carvalho e Silva, org., Homenagem a Manuel Bandeira I9861988, Niterói: Presença Edições, pp. 365-367.

Jiménez, Juan Ramón (2005). Obra poética, Madrid: Espasa Calpe. Prólogo de Victor García de la Concha y edición de Javier Blanco y Teresa Gómez Trueba.

Jiménez, Juan Ramón (2006). Música de otros (Traducciones y paráfrasis), Galaxia GutenbergCírculo de Lectores.

Martini, Maria de Lourdes (I989). «Bandeira, tradutor do espanhol». En Maximiano de Carvalho e Silva, org., Homenagem a Manuel Bandeira I9861988, Niterói: Presença Edições, pp. 423-425.

Milliet, Sérgio (1945). Diário Crítico, $3^{\circ}$ vol., São Paulo: Livraria Martins Editora.

Monteiro, Adolfo Casais (1958). Manuel Bandeira, Río de Janeiro: Ministério da Educação e Cultura.

Paes, José Paulo (1990). «Bandeira tradutor ou o esquizofrênico incompleto». En Tradução: $A$ Ponte Necessária, São Paulo: Editora Ática, pp. $55^{-66 .}$

Pereira, Paulo Roberto Dias (1995). «Manuel Bandeira: do eterno ao contingente». En Celine da Cunha Pereira; Paulo Roberto Dias Pereira, orgs., Miscelânea de estudos lingüísticos, filológicos e literários in Memoriam Celso Cunha, Río de Janeiro: Nova Fronteira, pp. 883-908.

Pontiero, Giovanni (1962). «Manuel Bandeira and the Browning Sonnets». En Pilar Orero; Juan S. Sager, The Translator's Dialogue. Giovanni Pontiero, Amsterdam-Philadelphia: John Benjamins Publishing Company, 1997, pp. I-5

Pontiero, Giovanni (I964). "Manuel Bandeira and Shakespeare's Macbeth». En Pilar Orero; Juan C. Sager, The Translator's Dialogue. Giovanni Pontiero, Amsterdam-Philadelphia: John Benjamins Publishing Company, 1997, pp. 7-15.

Ramos, Maria Celeste Thomazello (I998). «Elizabeth Bishop e a releitura de Bandeira». Cadernos de Tradução, III, pp.I7I-I8I.

Renault, Abgar (I936). «Notas à margem de algumas 
traduções de Manuel Bandeira». En Maximiano de Carvalho e Silva, org., Homenagem a Manuel Bandeira I986-I988, Niterói: Presença Edições, pp. 25-3r. Primero publicado en Homenagem a Manuel Bandeira, Río de Janeiro: Tipografia do Jornal do Commercio.

Rónai, Paulo (2005). «Notes toward a history of literary translation in Brazil». Translation Review, 69, pp. 49-53.

Rossi, Giuseppe Carlo (1970). «Manuel Bandeira, traductor de Sor Juana Inés de la Cruz». En Actas del Tercer Congreso Internacional de Hispanistas, vol. III, México: El Colegio de México, pp. 765778.

Rossi, Giuseppe Carlo (I97I). «Manuel Bandeira, traductor e intérprete de Sor Juana Inés de la Cruz». Revista de Filología Española, 54, pp. IO7-I2I.
Sager, Juan C. (1966). «A Brazilian Poet's Approach to the Translation of German Poetry». Babel, I2, pp. 198-204.

Silva, Beatriz Folly e; Lessa, Ma Eduarda de Almeida Viana (1989). Inventário do Arquivo Manuel Bandeira, Río de Janeiro: Fundação Casa de Rui Barbosa, I989.

Teles, Gilberto Mendonça (1985). Estudos de Poesia Brasileira, Coimbra: Livraria Almedina.

Wanderley, Jorge (I988). A Tradução do Poema entre Poetas do Modernismo: Bandeira, Guilherme de Almeida, Abgar Renault, Río de Janeiro: Pontifícia Universidade Católica.

Wyler, Lia (2003). Linguas, Poetas e Bacharéis (Uma crónica da tradução no Brasil), Rocco: Río de Janeiro, 2003. 